\title{
Cuando son muchas las voces *1
}

\author{
MANUEL CRUZ \\ Universidad de Barcelona
}

Resumen. Tras una inicial aproximación a la génesis del concepto de responsabilidad, génesis en la que se empiezan a percibir algunos de los rasgos del mismo que terminarán por hacerse explícitos en nuestros días, el trabajo se centra en señalar las implicaciones ( $\mathrm{y}$, sobre todo, las consecuencias) que tiene adscribir decididamente la responsabilidad a la época moderna y, en concreto, al surgimiento de la civilización industrial. Acaso una de las más importantes sea la de obligarnos a plantear toda una serie de asuntos en conexión necesaria con otro tema-eje del pensamiento moderno, el de la identidad. Junto a dicho tema, en el texto quedan apuntados otros, como el de la justa escala en la que abordar tales asuntos (o, lo que viene a ser lo mismo, el problema de las presuntas responsabilidades colectivas) o el del mal, por citar sólo dos, cuya envergadura puede servir como indicador de la importancia que presenta el concepto de responsabilidad en el pensamiento contemporáneo.
ABSTRACT. The work departs from an approach to the genesis of the concept of responsibility. Some features of the concept that have today become obvious can already come into sight in this first approach. The work devotes itself then to point out the implications (and, most of all, the consequences) involved in openly adscribing responsibility to the Modern Age and to the rise of industrial civilization. One of these main consequences is perhaps to have to deal with a number of theoretical topics in a necessary connexion with another axial topic of modern thought, namely, identity. Besides, the essay points also to a number of topics, such as the problem of the alleged collective responsibilities and also that of evil, just to quote two of them, whose magnitude may serve as an indicator to the relevance of the concept of responsibility in contemporary thought.

* Los trabajos aquí recopilados que versan sobre «Ética y responsabilidad» son una muestra de los materiales allegados al curso de la Universidad Internacional Menéndez Pelayo, coordinado por Roberto R. Aramayo y María José Guerra, que tuvo lugar en Tenerife en abril de 2001 y que serán editados en un volumen colectivo bajo el título de Los laberintos de la responsabilidad.

I Reincido aquí -en parte obligado por la amable presión de Roberto R. Aramayo- en una temática a la que ya dediqué en su momento algunos trabajos. Tanto en mi libro Hacerse cargo. Sobre responsabilidad e identidad personal (Barcelona, Paidós, 1999), passim, como en el anterior ¿A quién pertenece lo ocurrido? (Madrid, Taurus, 1995) probablemente aparezcan - en germen, insinuados, o tal vez incluso bajo formulaciones decididamente próximas - algunos de los argumentos que planteo en lo que sigue. Me gustaría pensar que el peligro de reiteración queda compensado por el hecho de que tales argumentos están puestos aquí al servicio de una estrategia discursiva diferente, $o$, lo que vendría a ser casi lo mismo, pretenden configurar un trenzado de ideas específico, distinto al que se presentó en los lugares mencionados. 
El tema de la responsabilidad no es un tema que pueda resolverse apelando a elementos indiscutibles, unánimemente aceptados o reconocidos por cualesquiera interlocutores. Casi me atrevería a sostener que, al contrario, se ha constituido en los últimos tiempos en el territorio de una viva confrontación teórica ${ }^{2}$. ¿Qué hay en cuestión en la pregunta por la responsabilidad que hace que provoque un tan encendido debate entre filósofos? Como casi siempre (entre filósofos, claro), las ideas subyacentes, los supuestos básicos en los que se apoya la propia pregunta, el entramado de conceptos y valoraciones que operan a modo de condiciones básicas de inteligibilidad de la interrogación misma.

\section{La responsabilidad, un invento moderno}

Hay un principio general de obligada aplicación en este caso, so pena de malentender gravemente el asunto. De cualquier pregunta cabe afirmar que es una pregunta fechada, pero no todas quedan por un igual determinadas por dicha ubicación temporal. La pregunta por la responsabilidad accede a las condiciones de posibilidad teórica en un momento determinado de desarrollo de la sociedad moderna o, lo mismo con otras palabras, viene indisolublemente ligada a un cierto desarrollo de la misma. El término responsabilidad - como ha señalado Jorge Riechman en otro contexto ${ }^{3}$ - es de origen relativamente reciente. $\mathrm{El}$ adjetivo castellano responsable es más antiguo que el sustantivo abstracto responsabilidad, pero en cualquier caso ambos son posteriores a 1700. Así, el Breve diccionario etimológico de la lengua castellana de Joaquín Corominas data la primera aparición documentada de responsable en 1737 y adjudica el sustantivo responsabilidad al siglo XIX. La consideración filológica en este caso corre paralelo al desarrollo mismo de la idea. En particular, el nombre abstracto no adquiere importancia hasta hace poco: responsibility apareció en inglés en 1787, y responsabilité lo hizo en francés once años más tarde. Repárese en lo que importa de estos datos: las connotaciones de la palabra en inglés y en francés son, en realidad, contemporáneas de la Revolución Industrial y han ejercido una fuerte influencia en castellano.

La puntualización debiera servirnos para no incurrir en la tan reiterada identificación entre responsabilidad y culpa. No es el momento de reincidir en esa discusión, pero resulta inexcusable recordar lo que a ambas separa.

2 Aunque sólo sea a título de mero indicador de refuerzo de este apresurado diagnóstico podríamos mencionar el hecho de que el reciente libro de Remo Bodei, La filosofía del Siglo XX (Madrid, Alianza, 2001), finalice su último capítulo, titulado «Mirando hacia adelante», precisamente con el epígrafe «El retorno de la responsabilidad».

3 Jorge Riechmann, «Ética y ecología», en el volumen colectivo Propuestas desde la izquierda, Madrid, Fundación de Investigaciones Marxistas, 1999. 
Tal vez si quisiéramos englobar en un solo dibujo - de trazo grueso, ciertamente - los diversos rasgos que diferencian ambos conceptos, tendríamos que referimos a la verticalidad de uno frente a la horizontalidad del otro, al carácter necesariamente intersubjetivo, dialógico, de la responsabilidad, frente al posible solipsismo propiciado por la culpa - que, en ese sentido, propende más bien a la intrasubjetividad-. Porque mientras ésta, en determinados contextos, es un asunto que únicamente tiene que ver con el sujeto, y con la interiorización que el mismo hace de la norma (lo que permite el fenómeno por el cual el más cruel de los criminales puede llegar a declarar, sin mentira ni violencia interior alguna, que no se siente culpable de nada), la responsabilidad no puede plantearse en términos de una hermenéutica privada, no es un negocio en el que el sujeto despache a solas con la norma. $\mathrm{La}$ responsabilidad, como nos recuerda la etimología del término, es estructuralmente intersubjetiva. Sin un ante quién responder, esto es, sin alguien que nos exija respuesta, que nos interpele con su reclamación, no hay responsabilidad posible.

Esta dimensión intersubjetiva o, dando un paso más, colectiva, pública, del mecanismo de la responsabilidad no finaliza aquí. El hecho de que la responsabilidad se puede delegar, acordar o incluso contratar (¿qué hacemos, si no, cuando firmamos la póliza de seguro del coche?) nos da la indicación adecuada para lo que queremos señalar. En la medida en que responsable es aquel -o aquella instancia - que se hace cargo de la reparación de los daños causados, la generalización de ese mecanismo informa de un cambio de actitud por parte de la sociedad. Un cambio que podría sintetizarse así: a partir de un cierto momento de desarrollo de las sociedades modernas, se asume que, con independencia de quien pueda ser el culpable, cualquier mal debe ser reparado.

No es obvia ni trivial semejante actitud. Durante la mayor parte de la historia de la humanidad, los hombres tendían a reaccionar ante el dolor, la catástrofe o la injusticia en una clave de resignación o de fatalidad que, en el mejor de los casos, posponía a una vida ultraterrena la reparación de los sufrimientos padecidos en ésta. Hoy hemos incorporado a nuestra mentalidad, a nuestro sentido común, algo tal vez más importante aún que el principio de que el delito no debe quedar impune, y es la idea de que el mal (aunque sea el mal natural, por decirlo a la vieja manera, esto es, aquél sin responsable personal alguno posible) debe ser subsanado ${ }^{4}$. La

${ }^{4}$ Cabe, desde luego, cuestionar en qué medida esa idea se ve o no materializada, pero ésa sería otra discusión, que no afectaría al contenido de lo que se ha afirmado. Que nuestra actitud respecto al mal haya variado es una afirmación que no queda falseada por la frustración de nuestras expectativas. De ahí que no sea contradictorio sostener lo anterior y admitir al mismo tiempo que tal vez Kundera lleve una parte de razón cuando escribe en La broma: «... la mayoría de la gente se engaña mediante una doble creencia errónea: cree en el eterno recuerdo (de la gente, de las cosas, de los actos, de las naciones) y en la posibililidad de reparación (de los actos, de los errores de los pecados, de las injusticias). Ambas creencias son falsas. La realidad es precisamente al contrario: 
idea no tiene garantizado su cumplimiento en ninguna ley cuasi-natural, ni menos aún en una (afortunada) necesidad histórica. Es, más bien, una promesa que forma parte - y parte sustancial - del sueño de la Modernidad. Hasta el punto que bien pudiéramos denominarla nuestra particular promesa constituyente.

\section{2. ¿Funciona el invento?}

Venimos obligados, ciertamente, a pensar sobre las consecuencias remotas de nuestras acciones, obligación que se deriva del nuevo poder adquirido por el hombre contemporáneo. Pero el cambio de escala, la preocupación por el futuro del planeta, de la especie o incluso de la vida como tal, lejos de eximirnos de otro orden de consideraciones, nos devuelve a ellas como el único referente previo del que partir. La especie humana no puede ser entendida como el nuevo sujeto al que referir la responsabilidad, como si la escala fundacional, la de los agentes particulares, hubiera quedado obsoleta, hubiera estallado en mil pedazos, pulverizándose. Eso equivaldría a una modalidad de huida hacia adelante, que dejaría sin pensar la sustancia misma del asunto.

Plantear la conveniencia de tomar a los sujetos individuales como elemento fundamental sobre el que basar toda pesquisa en este terreno en modo alguno se debe confundir con una apología - ni siquiera con una fundamentación previa - del individualismo. El individuo es, propiamente, aquella instancia más acá de la cual no se puede retroceder, porque configura un todo, una unidad, una realidad conjunta (indivisible, en sentido literal). A la afirmación de los individuos, si acaso, se le podrá reprochar otra cosa - pero entonces el reproche estará hecho desde un lugar distinto-. Se le podrá acusar de estar ontologizando, cosificando, atribuyendo una ficticia identidad, a lo que de suyo es un agregado, disperso y contradictorio, de pulsiones, instintos, razones e intereses (entre otros materiales de derribo ${ }^{5}$ ). Pero esta objeción, que alcanzó sus más altas cotas de popularidad en la década de los ochenta, merced sobre todo a la colaboración sincronizada y publicísticamente muy rentable de un cierto postestructuralismo y una cierta postmodernidad, ha ido perdiendo intensidad en los últimos años, acaso porque las condiciones de posibilidad, tanto teóricas como reales, de ambos se han ido desvaneciendo. Probablemente la tarea primordial hoy sea dilucidar,

todo será olvidado y nada será reparado. El papel de la reparación (de la venganza y del perdón) lo lleva a cabo el olvido. Nadie reparará las injusticias que se cometieron, pero todas las injusticias serán olvidadas» (M. Kundera, La broma, Barcelona, Seix Barral, p. 303).

5 Así entre las definiciones peyorativas que durante un cierto tiempo se le dedicaron a la noción de sujeto podríamos mencionar las de «mero constructo», «artificio narrativo», «efecto de estructuras», cuando no «basura biográfica», entre otras del mismo tenor. 
de una parte, qué sujeto y de qué manera puede asumir el protagonismo al que hemos hecho referencia y, de otra, bajo qué descripción podemos continuar hablando de responsabilidad.

Todavía es posible perseverar en el tópico de que la identidad es una construcción ${ }^{6}$, pero a sabiendas de que dicho tópico presenta ya una muy escasa utilidad si lo que pretende es dar a entender que hay otras realidades de las que no cabe predicar esa condición de constructo, o que la auténtica dimensión básica previa se halla en un nivel más elemental, o más simple, de nuestra realidad. Ubicación esta última que, por lo general, terminaba teniendo, como uno de sus inevitables corolarios teóricos, el desdibujamiento del vínculo a postular en relación a las acciones ( $i$ a qué elemento del desestructurado y confuso agregado que somos se podría atribuir la responsabilidad?). Ahora bien, el rechazo del señalado tópico (y, sobre todo, del uso que se ha hecho del mismo) no debiera impedirnos reconocer la utilidad crítica que ofrece intentar analizar, con la máxima atención y voluntad de conocimiento, la real articulación de elementos que hace de cada uno de nosotros lo que efectivamente somos, con la esperanza de que de ahí pueda surgir una idea adecuada del significado del término responsabilidad.

El sujeto, si se me permite que lo resuma abruptamente, no es una mera posibilidad, una opción o, muchísimo menos, un capricho. Si se parece a algo es a un destino, a una necesidad ineludible, a una insoslayable condición de posibilidad de nuestra existencia. Es esa instancia, a la que antes se aludió, que se hace cargo del proceso. Hasta el final, por cierto. La subjetividad de la que habla la filosofía, el sujeto moral del que trata una parte de la misma, no es una instancia menor, técnica. No es meramente el agente al que atribuimos la significatividad de las diferentes acciones. Es más que la instancia a la que ir atribuir los eventos: es alguien que se hace cargo de su propia vida, hasta el límite máximo que seamos capaces de pensar. A él le pertenece todo cuanto ocurre, incluido él mismo.

Así lo ha entendido, por ejemplo, Jean Amèry ${ }^{7}$ al partir precisamente de la pregunta: «¿a quién pertenece el ser humano?». Aunque él sigue pensando que debe pertenecerse a sí mismo - y que, por tanto, lo que él prefiere llamar la muerte voluntaria (en vez de suicidio) es una muerte libre y una cuestión meramente individual- repara con agudeza en una contradicción: «por un lado, la fría indiferencia que muestra la sociedad respecto al ser humano, y, por otro, la cálida preocupación por él cuando se dispone a abandonar voluntariamente la sociedad de los vivos». La cuestión es si de su afirmación de que en ese momento el ser humano está solo consigo mismo se deriva necesariamente que ante ese hecho, como afirma el propio autor, «la

${ }_{6} \mathrm{Al}$ abuso en la tendencia a considerar construcción social a cualquier cosa que sea de la que se hable le ha dedicado un agudo libro lan Hacking, ¿La construcción social de qué?, Barcelona, Paídós, 2001.

7 En su libro Levantar la mano sobre uno mismo, Valencia, Pre-Textos, 1999. 
sociedad debe callar». Pero repárese en lo que verdaderamente importa: «La exigencia de la vida ordena [...] huir de una vida indigna, inhumana y sin libertad. De este modo la muerte se torna vida, así como la vida desde el nacimiento es ya morir. Y de pronto la negación se hace positividad, aunque sea completamente inútil. Lo que cuenta es la opción del sujeto» (cursiva, M. C.).

\section{Responsabilidad, finalmente}

Nos hemos deslizado, de forma deliberada, hacia magnitudes mayores, hacia una escala muy alejada del minimalismo filosófico más o menos imperante en ciertos ambientes. Está claro que una tal audacia sólo se puede plantear desde la convicción, alternativa, de que únicamente una mirada global se encuentra en condiciones de dotar de todo su sentido a este planteamiento. En otro lugar ${ }^{8}$ he intentado extraer las consecuencias que se derivan de tan abarcadora concepción de la subjetividad. Postular la responsabilidad por la propia vida - afirmación en la que hemos terminado desembocandoimplica, en efecto, colocarse decididamente frente a tantos como abogan por la desresponsabilización absoluta (de sí mismos, claro: no en otra cosa se sustancia el victimismo generalizado del que habla Bruckner en su libro $L a$ tentación de la inocencia ${ }^{9}$ ). Viene a significar una forma específica de reclamar la kantiana mayoría de edad para los hombres. Pero, del otro lado, la propuesta planteada también supone cambios.

Porque, más allá de la cuestión ¿de qué somos responsables? —en alguna medida (por pequeña que sea) respondida en todo lo precedente-, persiste otra pregunta, complementaria de la primera a la hora de abordar el asunto de la responsabilidad, y es la de ante quién somos responsables. A esta otra cuestión a menudo ha tendido a responderse en una clave, a nuestro entender, de todo punto equivocada, consistente en dar por descontado que somos responsables ante los que sufren, que su sufrimiento en cuanto tal, con absoluta independencia de su origen o su autoría, nos interpela. Pues bien, se impone rescatar la apelación al sufrimiento ajeno de la farisaica instrumentalización moralista de que suele ser objeto. Tomarse en serio dicha apelación, en definitiva. El sufrimiento no convierte en bueno a quien lo padece, ni le exime de responder del daño que haya podido provocar en otro momento. Por lo mismo, de poco sirve llenarse la boca constantemente con el recordatorio de los padecimientos del prójimo, como si el mero alinearse en contra de los mismos colocara a quien presenta la formulación en un lugar teórico inobjetable. Las apelaciones meramente emotivistas suelen incurrir en esa argucia argumentativa que Nietzs-

\footnotetext{
8 «Acerca de la necesidad de ser responsables», Introducción a M. Cruz y R. R. Aramayo, $E l$ reparto de la acción, Madrid, Trotta, 1999.

9 Barcelona, Anagrama, 1995.
} 
che llamaba «la prueba del placer», consistente en actuar como si el mejor respaldo de una afirmación no fuera su correspondencia con los hechos, sino más bien el grado de satisfacción y autocomplacencia que infunde a quien la ha formulado, gratificado hasta el límite por haber dado expresión a tan elevados sentimientos.

La responsabilidad no debe acogerse a ese orden de argumentaciones o fundamentos, por más que presenten una apariencia de evidencia intuitiva. En realidad, dicha apariencia se desprende, no tanto de la cosa misma, como de su inscripción en el entramado de tópicos y valoraciones acríticas que constituyen el sentido común de las gentes de esta época. Pero establecer un tal orden de vinculaciones debe ser considerado, desde el punto de vista del desarrollo de las ideas, un auténtico retroceso, en la medida en que reincide, tácitamente, en una identificación entre responsabilidad y culpa, de la que la primera, desde sus orígenes, en todo momento intentó escapar. Ni siquiera la responsabilidad moral —la más sensible, por razones históricas, a ello- debiera aceptar dicha identificación. La responsabilidad no se puede pensar bajo la figura de la deuda, ni cabe convertirla en un gesto reactivo. Es más bien la actitud más afirmativa que estamos en condiciones de pensar. Por lo mismo, declararse responsable no es un imperativo cuya legitimidad última derive de ningún tipo de trascendencia. Antes bien al contrario, se pretende uno de los gestos seculares por excelencia.

De ahí que aludiéramos antes a la promesa de la Modernidad, a la que nos atrevimos a definir como nuestra particular promesa constituyente, y tal vez ahora se entienda mejor la alusión, esto es, se vea más claro a dónde conduce. Es cierto que esa promesa siempre ha vivido amenazada por una mórbida y enfermiza querencia hacia la disolución y el caos que alguien podría pensar que es indisociable de la naturaleza humana. Pero tal vez la clave esté en otra parte. Tal vez lo que necesitáramos pensar es hasta qué punto tanta resistencia - tanta dificultad para cumplir lo largamente anunciado - no estará expresando en último término la envergadura del desafío ilustrado, la ambición del anhelo moderno. Como en algún otro momento hemos tenido la oportunidad de señalar ${ }^{10}$, quizá no haya habido en la historia fantasía más desatada, sueño más loco, que el de un mundo regido por los principios de la razón. Tal vez nunca desvarió tanto el hombre como cuando aspiró a un futuro en el que las relaciones no vinieran determinadas por la riqueza o el dominio, ni el conocimiento nublado por la superstición. O acaso, simplemente, midió mal sus fuerzas y terminó pagando muy cara su arrogancia de enfrentarse a uno de los miedos más ancestrales de la humanidad, el miedo a hacerse cargo de las riendas de su propio destino. A declararse responsable de él, finalmente.

${ }^{10}$ En mi «Prólogo» a M. Cruz (comp.), Tolerancia o barbarie, Barcelona, Gedisa, 1998. 
Pero que esto no se entienda como una defensa por mi parte de progresismo racionalista ingenuo ${ }^{11}$ - defensa que, de existir, pondría seriamente en entredicho todo lo que se ha intentado defender hasta aquí-. Las anteriores referencias a las diversas formas (artificiales, por remachar el clavo) de construir la identidad, o de pensar la pertenencia, pretendían advertir de este peligro. Que es, por lo demás, un peligro bien real, incluso próximo y acechante, que a menudo se sirve de argumentos de suyo legítimos y honorables (como, a la inversa, le sucede al relativismo, según ha señalado Antonio Valdecantos ${ }^{12}$ ). Pienso en los argumentos del cosmopolitismo, que se ven desdibujados y mal interpretados por una identificación errónea entre democracia y universalidad ${ }^{13}$.

Sólo si pensamos adecuadamente el tránsito entre los individuos y sus comunidades (grupos, etc.), esto es, sólo si entendemos bien la constitución de eso que Rorty gusta de llamar el nosotros ${ }^{14}$, estaremos en condiciones de empezar a elaborar alguna idea válida (y viable) de responsabilidad colectiva. En cualquier caso, y entre tanto, mejor optar por las formulaciones prudentes y las categorías modestas. Mejor hablar, siguiendo las indicaciones de Gadamer, a quien tanto debemos, de horizontes (a propósito de lo histórico) o de tolerancia (a propósito de la sociedad).

Llevan razón quienes señalan que, mientras no alcancemos el deseable grado de ilustración en nuestra convivencia, la categoría de tolerancia continúa siendo irrenunciable. Sólo que ahí yo me atrevería a proponer un pequeño matiz, en el que creo que se juega un aspecto relevante de la cuestión. En vez de decir que esta tolerancia constituye una versión debilitada de la razón ilustrada, prefiero - manías de filósofos- otra formulación. Una formulación en la que, a partir de la evidencia de nuestra necesidad de la tole-

11 «... si la modernidad se define como fe incondicional en el progreso, en la técnica, en la ciencia y en el desarrollo económico, entonces esa modernidad está muerta», Edgar Morin, Los siete saberes necesarios para la educación del futuro, Barcelona, Paidós, 2001, p. 86.

12 En su estimulante libro Contra el relativismo, Madrid, Visor, 2000.

13 Disyuntiva que, para mayor confusión, a menudo se presenta como equivalente a la disyuntiva entre particularismo y universalismo. A este respecto, Amy Gutmann ha calificado de «moralmente equivocada y políticamente peligrosa» la idea de que debemos elegir entre «ser, por encima de todo, ciudadanos de nuestra propia sociedad o, por encima de todo, ciudadanos del mundo», A. Gutmann, "Ciudadanía democrática» en ibidem, p. 89. Por su parte, Terry Eagleton tiene escrito en La idea de cultura, Barcelona, Paidós, 2001, p. 120: «no se trata de elegir entre ser ciudadano del mundo, o ser miembro de tu propia vecindad. Todos somos ambas cosas en diferentes situaciones y en relación a diferentes fines».

14 Esto es, entender dicha constitución en el marco de la construcción de un nuevo concepto de solidaridad basado en la lucha contra cualquier forma de crueldad. En ese marco hay que «saber quitar importancia al mayor número de diferencias tradicionales (de tribu, de religión, de raza, usos y otras semejantes) frente a la semejanza en el dolor y en la humillación, en el saber incluir en la esfera del "nosotros" a personas inmensamente diferentes de nosotros mismos", R. Rorty, Contingencia, ironía y solidaridad, Barcelona, Paidós, 1991, p. 210. Asimismo de interés para lo que se ha planteado aquí resulta el más reciente libro de Richard Rorty, Forjar nuestro país, Barcelona, Paidós, 2000. 
rancia se concluya algo muy próximo a que la razón ilustrada sólo puede ser débil. $\mathrm{O}$, enunciado a la inversa, que las pretensiones de construcción de una razón fuerte siempre han representado en realidad el intento de hacer pervivir viejas expectativas e ideales, de matriz trascendentalista, bajo los ropajes del inmanentismo (científico o materialista).

¿Equivale esto a reconocer que mi concepción del ideal ilustrado impide poder determinar positivamente, sino a lo sumo por exclusión, el lugar universal de entendimiento que declaro anhelar? No es eso con exactitud. Yo no diría que el lugar universal de entendimiento se determina más por exclusión que positivamente. Diría que se determina más tentativamente que de forma programática. Como, por lo demás, no podría ser de otra manera, una vez que hemos asumido que la universalidad a la que apunta la política democrática es un lugar que no está ocupado por nadie, y al que sólo nos podemos aproximar por la vía de asumir e intentar resolver los conflictos existentes, no por la de imponer por arriba una abstracta condición cosmopolita (o equivalente). Pero aceptar tal propuesta implica desplazar el espacio de la discusión, abandonar un ámbito de debates cuyo agotamiento el paso tiempo se habría encargado de revelar: debates de carácter normativo o fundamentador, pongamos por caso. Ahora parece tratarse, abiertamente, de otra cosa. $\mathrm{O}$, tal vez, de la misma cosa de siempre: nuestro problema, en resumidas cuentas, sigue siendo no qué debemos hacer, sino qué queremos hacer. 